\title{
Microsurgical Gross Total Resection of a Large Residual/Recurrent Vestibular Schwannoma via Translabyrinthine Approach
}

\author{
Sima Sayyahmelli ${ }^{1}$ Joseph Roche ${ }^{1}$ Mustafa K. Baskaya ${ }^{1}$ \\ ${ }^{1}$ Department of Neurological Surgery, University of Wisconsin \\ Medical School, Madison, Wisconsin, United States \\ J Neurol Surg B 2018;79(suppl S5):S387-S388. \\ Address for correspondence Mustafa K. Baskaya, MD, Department of \\ Neurological Surgery, University of Wisconsin Medical School, K4/834 \\ CSC, 600 Highland Avenue, Madison, WI 53792-0001, United States \\ (e-mail: baskaya@neurosurgery.wisc.edu).
}

\begin{abstract}
Keywords

- cerebellopontine angle

- vestibular schwannoma

- microsurgery

- recurrent

- resection

- translabyrinthine approach
\end{abstract}

Although, gross total resection in large vestibular schwannomas is an ideal goal, subtotal resection is frequently performed due to lack of expertise, concerns for facial palsy, or overuse of stereotactic radiation. In this video, we present a 31-year-old man with a 7-year history of tinnitus, dizziness, and hearing loss. The patient had a subtotal resection of a $2.5 \mathrm{~cm}$ right-sided vestibular schwannoma via retrosigmoid craniotomy at an outside hospital. He was referred for further surgical resection due to the increased size of the tumor on surveillance magnetic resonance imagings (MRIs) and worsening symptoms. MRI showed a residual/recurrent large schwannoma with extension to the full length of the internal acoustic canal and brain stem compression. He underwent microsurgical gross total resection via a translabyrinthine approach. The facial nerve was preserved and stimulated with $0.15 \mathrm{~mA}$ at the brainstem entry zone. He awoke with House-Brackmann grade III facial function, with an otherwise uneventful postoperative course. In this video, microsurgical techniques and important resection steps for this residual/recurrent vestibular schwannoma are demonstrated, and nuances for microsurgical technique are discussed.

The link to the video can be found at: https://youtu.be/a0ZxE41Tqzw.
Conflict of Interest

None.

Disclosure of Funding

None.

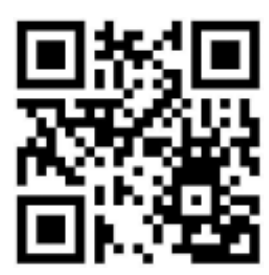

received

May 31, 2018

accepted

August 12, 2018

published online

September 25, 2018 www.thieme.com/skullbasevideos

www.thieme.com/jnlsbvideos

DOI https://doi.org/

10.1055/s-0038-1669971.

ISSN 2193-6331.
๑) 2018 Georg Thieme Verlag KG
Stuttgart · New York

License terms

(c) (1) $\ominus$ (\$) 


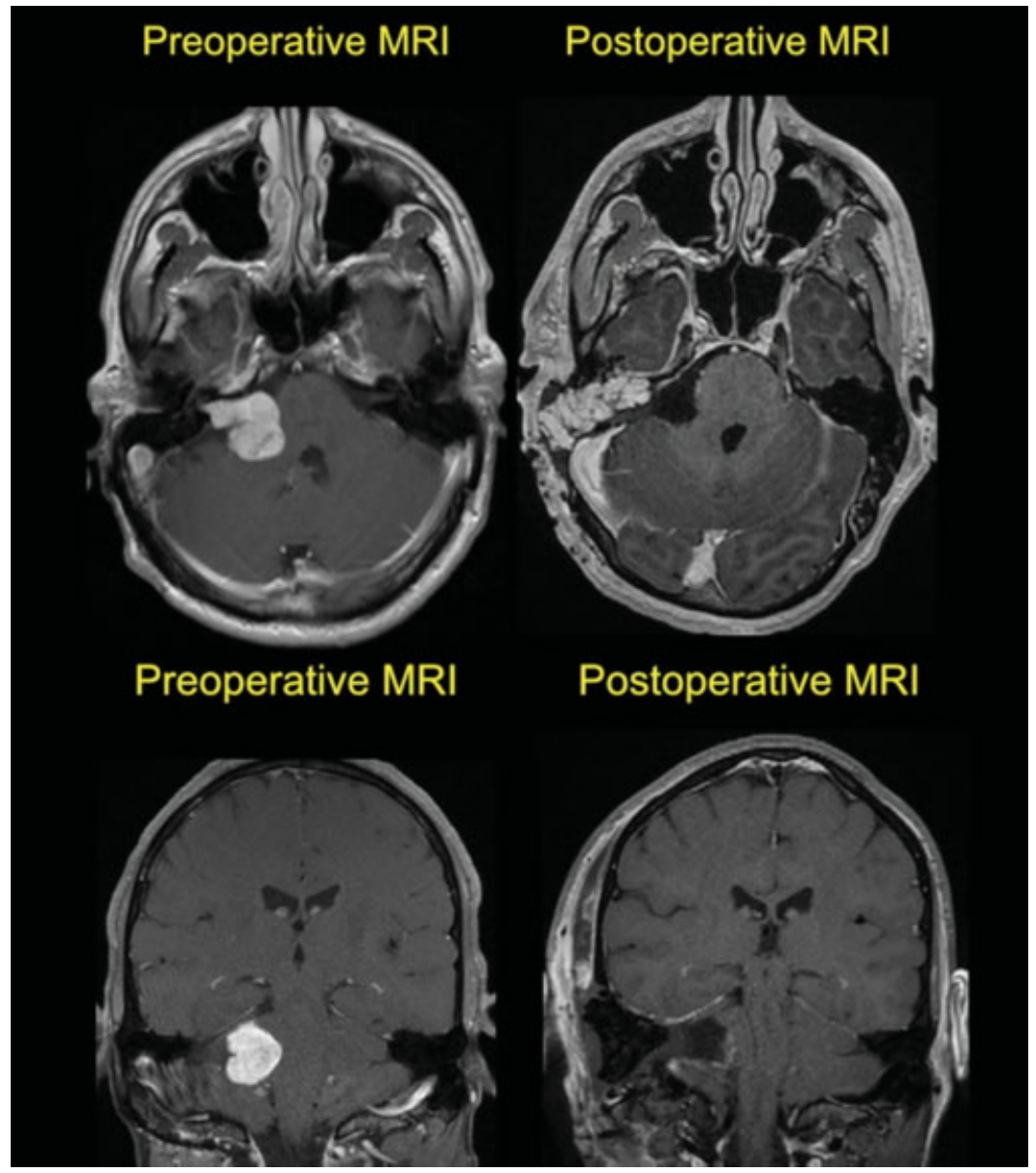

Fig. 1 Pre and postoperative magnetic resonance imaging.

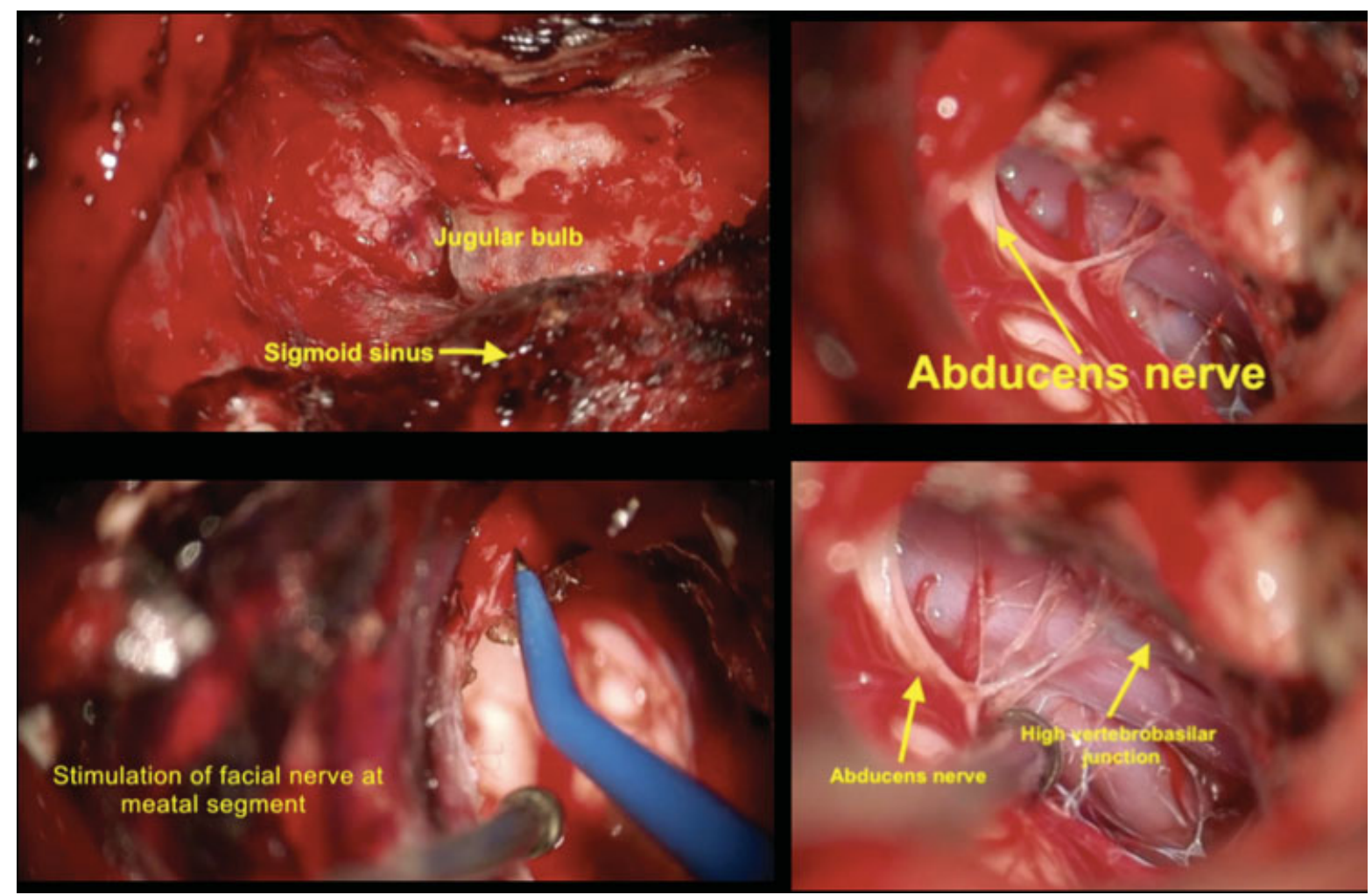

Fig. 2 Intraoperative images. 